\title{
Marx e as "robinsonadas" da Economia Política
}

Marx and Crusoe stories of Political Economy

André Guimarães Augusto

Universidade Federal Fluminense

\begin{abstract}
This article reexamines Marx's critique of the Robinson Crusoe stories of Political Economy. Political Economy, according to Marx, starts from an isolated individual without social determinations. This is supposed to be the natural condition of mankind and this is personified by Robinson Crusoe on his island. Following Marx's ontological critique, Robinson Crusoe's stories of Political Economy are considered to be an illusory and theoretical representation covering the real conditions of capitalist society. In the first section of this article, the Robinson Crusue stories of Political Economy are reviewed, pointing to his conception of human nature and society. This section also shows that this is a lasting conception of man in economics. In the second section, we developed Marx's explanation for this conception of man through the method of ontological critique. Finally, in the last section it is suggested that Marx's critique of Robinson Crusoe stories of Political Economy doesn't imply the irrelevance of theoretical and ethical significance of individuals.
\end{abstract}

\section{Keywords}

individuals; political economy; ontological critique.

JEL Codes B14; B40; Z13.

\section{Resumo}

Neste artigo é resgatada a crítica de Marx às "robinsonadas" da Economia Política. Com isso, Marx observa que a Economia Politica toma como ponto de partida o indivíduo isolado e sem determinações sociais, o indivíduo tal como é supostamente posto pela natureza representado na imagem de Robinson Crusoé em sua ilha. Seguindo o método da crítica ontológica de Marx, as "robinsonadas" da Economia Politica são apreendidas como uma representação teórica ilusória de condições realmente existentes na sociedade capitalista. Na primeira parte do artigo, será resgatada a "robinsonada" da Economia Política, procurando-se sintetizar sua concepção de homem $e$ de sociedade. Será indicada também a perenidade dessa concepção no pensamento econômico, em seus traços gerais. Na terceira parte do artigo, é indicada a crítica ontológica de Marx às "robinsonadas" apontando sua origem nas condições reais da reprodução material na sociedade capitalista. Finalmente é resgatado o tema do indivíduo em Marx, indicando que a crítica de Marx às "robinsonadas" não implica que Marx não dê importância ou desconheça o indivíduo teórica e eticamente.

\section{Palavras-chave}

indivíduo; economia política; crítica ontológica.

Códigos JEL B14; B40; Z13. 


\section{Introdução}

$\mathrm{Na}$ introdução do Para a crítica da Economia Política e em O capital, Marx se refere às "robinsonadas" da Economia Política. Com isso, o autor observa que a Economia Política toma como ponto de partida o indivíduo isolado e sem determinações sociais, o indivíduo tal como é supostamente posto pela natureza, representado na imagem de Robinson Crusoé em sua ilha. Trata-se aqui de uma referência ao romance Robinson Crusoé, de Daniel Defoe, cuja primeira edição data de 1719.

A ideia do homem isolado, sem determinações sociais, surge primeiramente na filosofia política de Hobbes e Locke e é absorvida pela Economia Política, convertendo-se em sua pedra fundamental. Além disso, a Economia se torna crescentemente a cidadela da concepção do homem isolado, livre de determinações sociais. Seguindo o método da crítica ontológica de Marx, as "robinsonadas" da Economia Política são apreendidas neste artigo como uma representação teórica ilusória de condições realmente existentes na sociedade capitalista. Assim, o termo "ilusório" aqui não ser refere a um erro cognitivo ou má-fé dos economistas que adotam essa representação do homem, mas sim às ilusões que são necessariamente geradas pelas condições de reprodução da vida material na sociedade capitalista.

$\mathrm{Na}$ primeira parte deste artigo, será examinado o papel de Robinson Crusoé na literatura como modo de expressão da burguesia ascendente e suas antecipações sob forma ficcional da concepção de natureza humana contida na Economia. Na seção seguinte, serão resgatadas as "robinsonadas" da Economia Política, procurando-se sintetizar sua concepção de homem e de sociedade. Será indicada também a perenidade dessa concepção em seus traços gerais no pensamento econômico dominante. Na terceira parte do artigo, é indicada a crítica ontológica de Marx às "robinsonadas", apontando sua origem nas condições reais da reprodução material na sociedade capitalista. Finalmente, é esboçado o tema do indivíduo em Marx, indicando que a crítica às "robinsonadas" não implica que Marx não dê importância ao indivíduo teórica ou eticamente ou o desconheça, como faz crer tanto a leitura tradicional da obra de Marx como a sua desqualificação pelos críticos. 


\section{Robinson Crusoé de Defoe}

Nascido em 1660, em uma família de comerciantes, Daniel Defoe fez carreira no comércio de importação e exportação, sendo levado à falência e à prisão por dívidas por alguns dias em 1692 (Richetti, 2005, p. 16). De família protestante, Defoe contou com suas ligações na corte do rei protestante William III - que substitui o rei católico James II em 1688 - para sua recuperação financeira, estabelecendo uma manufatura de tijolos e telhas (Richetti, 2005). No final da última década do século XVII, Defoe inicia uma carreira de jornalista político, em apoio ao governo de William III. Defoe foi um inovador no jornalismo, tornando-se o primeiro jornalista de opinião, os modernos colunistas.

Robinson Crusoé é a primeira obra de ficção de Defoe. Especula-se que a motivação de Defoe para estrear uma carreira de escritor de ficção era de natureza financeira, vendo a possibilidade de lucro na publicação da história (Richetti, 2005). Com o sucesso comercial de Robinson Crusoé, Defoe lançou dois livros como sequência nos anos seguintes, indicando assim também o início da literatura comercial.

O livro de Defoe marcou um ponto de inflexão na história do romance como forma artística da burguesia. Robinson Crusoé tem todas as características do que Lukács (2009), seguindo Hegel, denominou de "a epopeia burguesa". O romance é para a sociedade burguesa o que a epopeia foi para a sociedade da Antiguidade grega; segundo Lukács, "é no romance que todas as contradições específicas desta sociedade são figuradas do modo mais típico e adequado" (Lukács, 2009, p. 193).

Robinson Crusoé marca o estabelecimento dos elementos formais do romance como "epopeia burguesa". Sua característica fundamental é o realismo, ao narrar uma história que tem a possibilidade de ser verdadeira. A experiência anterior de Defoe como jornalista colaborou para a adoção do realismo em seu livro, e, não por um acaso, a história de Robinson Crusoé é baseada em um fato real. O jornal The Englishmen publicou uma entrevista em 1711 com Alexander Selkirk, marinheiro escocês que chegou à Inglaterra depois de passar quatro anos sozinho em uma ilha no Chile (Richetti, 2005).

Em Robinson Crusoé e posteriormente no romance, as histórias tradicionais que refletem uma cultura, característica do classicismo predominante na literatura inglesa da época, são substituídas por um enredo que narra 
uma experiência individual (Watt, 1957). A epopeia burguesa é a epopeia de um indivíduo, ao contrário da epopeia homérica, em que a ação "é a luta de uma sociedade relativamente unida, de uma sociedade enquanto coletividade, contra um inimigo externo" (Lukács, 2009, p. 206). No romance, os tipos e as abstrações são substituídos por pessoas que agem em circunstâncias particulares. Aqui os personagens de ficção ganham nomes próprios, algo incomum na época (Watt, 1957). A história decorre em um fluxo temporal determinado, colocando assim a ação como seu elemento central (Lukács, 2009).

Mas o caráter realista também traz outros elementos e inovações presentes em Robinson Crusoé, além das estilísticas. Watt (1957) assinala que as características estilísticas dos primeiros romances ingleses, em especial o de Robinson Crusoé, replicam na especificidade do estético o empirismo de John Locke. De acordo com o empirismo, o conhecimento verdadeiro parte da experiência individual. Como assinala Richetti (2005, p. 203), o romance inglês do século XVIII "se situa entre o jornalismo popular" e o ensaio. A proximidade de Robinson Crusoé com a filosofia de Locke não é meramente casual: Defoe estudou em uma academia de protestantes dissidentes onde a filosofia de Locke era ensinada (Richetti, 2005).

O realismo inaugurado por Defoe em Robinson Crusoé não pode ser visto como mera descrição de um fato ou da vida particular. $O$ que o afasta do simples jornalismo e o aproxima do ensaio é justamente a "figuração realista do típico" (Lukács, 2009, p. 218). O próprio Defoe, na voz de Robinson Crusoé, afirma em Serious reflections, o último livro da série com o personagem publicado em 1720 , que sua história tem caráter alegórico ${ }^{1}$ (Watt, 1996, p. 149).

A figuração do típico e o caráter alegórico de Robinson Crusoé se referem à concepção de homem da classe burguesa em ascensão: ativo, empreender e naturalmente livre, em que este último atributo consiste na ausência de determinações sociais. $O$ isolamento na ilha é uma alegoria do isolamento do indivíduo como sua condição universal. O primeiro capítulo de Serious reflection se entitula [relata] "sobre a solidão", e nele Defoe afirma: "Me parece que a vida em geral é, ou deveria ser, um ato universal de solidão" (Watt, 1995, p. 150).

1 A alegoria consiste na transmissão de um significado abstrato ao significado literal de uma narrativa. Diferente da metáfora que é localizada, a alegoria se refere à totalidade de uma obra artística, sendo a parábola e a fábula duas formas de literatura alegórica. 
A vida como um ato de solidão e o estado natural do homem como do isolamento é apresentado inicialmente na filosofia de Hobbes. Nesta há uma primeira ruptura com a apreensão do homem como um animal social. Mas, para Hobbes, o homem ainda é um animal político em outro sentido. De acordo com Hobbes, o móvel das ações individuais é o desejo de dominar e de evitar a morte (Mac Intyre, 1996), mas o contrato social é necessário para a sobrevivência dos indivíduos. No estado de natureza de Hobbes e Locke, embora os indivíduos movidos pelos próprios interesses se confrontam uns com os outros. Nas condições históricas em que Hobbes e Locke se encontravam, o homem ainda não pode ser tido como completamente isolado, uma vez que o burguês ainda necessita do Estado para o crescimento da riqueza e em sua luta contra a aristocracia. Os vínculos sociais são reduzidos ao vínculo com o Estado, refletindo assim as condições da acumulação primitiva elaborada teoricamente no mercantilismo.

O Robinson Crusoé de Defoe leva a concepção do isolamento natural do homem ainda mais longe, eliminando qualquer vínculo social na caracterização da natureza humana. A despeito de Defoe ser um defensor do mercantilismo (Richetti, 2005), Robinson Crusoé é uma alegoria da concepção liberal de natureza humana, e sua ética utilitária seria posteriormente desenvolvida pela Economia. Diferentemente do estado de natureza de Hobbes e Locke, o estado de natureza ao qual Robinson é levado pelo naufrágio é um estado no qual ele só estabelece uma relação de dominação com a natureza, sem a presença de nenhum outro indivíduo. Ao contrário do indivíduo de Hobbes, que precisa do contrato social para sua sobrevivência, Robinson Crusoé é capaz de sobreviver apenas pelo esforço próprio e pelo uso da razão, sem necessidade de nenhum vínculo social imediato.

Elementos da ética puritana do trabalho estão presentes no estado de natureza em que Robinson se encontra na ilha. Ele sobreviveu ao isolamento com o trabalho contínuo, com a atividade incessante. Para Crusoé, o trabalho é a forma de aliviar a angústia da solidão, purgar-se do pecado de ter ido contra a vontade do pai e de obter recompensas. Seus confortos não são luxos, mas replicam a vida doméstica burguesa do século XVII e resultam de seu trabalho. Aqui o mito da acumulação primitiva idílica, presente já em Locke e que seria desenvolvido pela Economia Política clássica, aparece em forma ficcional. Crusoé torna-se proprietário da ilha por ter trabalhado nela; a propriedade no romance de Defoe resulta do trabalho próprio (Richetti, 2005). 
Crusoé, porém, não vive isolado na ilha todo o tempo em que se passa o romance. O caráter meramente utilitário dos vínculos sociais, típico da ideologia liberal, aparece claramente nos atos de Robinson Crusoé. Ele estabelece laços sociais de acordo com seu interesse material. Assim, Robinson abandona a família em busca de riqueza; Xury, o jovem que ajuda Robinson a escapar da escravidão no Marrocos, é vendido por ele como escravo; o mesmo tipo de relação utilitária é estabelecido com a sexta-feira. Em nenhum momento na história, Robinson parece movido por qualquer tipo de motivação social - como a benevolência de Hutchson -, necessidades emocionais ou instintos. $O$ indivíduo isolado, utilitarista, autointeressado e cuja racionalidade se restringe ao cálculo de custos e benefícios, nascia na ficção de Defoe antes de emergir e ser desenvolvido pela Economia Política.

\section{As "robinsonadas" da Economia Política}

A Economia Política clássica não faz referências ou analogias diretas com o personagem do romance de Defoe. De acordo com Screapanti e Zamagni (2005), Gossen foi o primeiro economista a usar explicitamente a metáfora de Robinson Crusoé. Mas a metáfora está presente implicitamente já em Adam Smith. Nos tempos "antigos e primitivos" de Smith, os membros de uma tribo já são postos como indivíduos que se relacionam através da troca (Smith, 1983, p. 74). Mais do que isso, esses indivíduos são livres de determinações sociais e são movidos pelos "instintos" e pelas "disposições" presentes na natureza humana imutável. Assim, os indivíduos são movidos pelo "self-love", pela consideração dos próprios interesses e do bem-estar.

De acordo com Smith, a propensão à troca seria uma consequência da capacidade de raciocinar e falar. ${ }^{2}$ Para ele, a troca é um meio de persuasão, de levar o outro a realizar o seu desejo convencendo a ele que obterá alguma vantagem, isto é, apelando a "consideração que eles têm de seu próprio interesse" ao seu "self-love", em lugar do apelo à benevolência.

2 Em suas Lectures on jurisprudence, Smith afirma explicitamente que a disposição à troca se baseia na "inclinação natural" à persuasão: "If we should enquire into the principle in the human mind on which this disposition of trucking is founded, it is clearly the naturall inclination every one has to persuade" (Smith, 1982, p. 306). 
Da mesma forma, Smith apresenta a divisão do trabalho como o resultado de um protocálculo de vantagens. Smith considera que um membro de uma tribo, nos tempos primitivos,

considera que pode obter mais gado e carne de caça do que conseguiria se ele mesmo fosse à procura deles no campo. Partindo, pois, da consideração do interesse próprio se especializa no que é mais hábil. [...] a certeza de poder permutar toda a parte excedente da produção [...] estimula cada pessoa a dedicar-se a uma ocupação especifica [...] (Smith, 1983, p. 74-75).

Todavia, as "robinsonadas" de Smith são apenas uma parte de sua obra, a exotérica, nos termos de Marx. Ao dispor a troca e a divisão do trabalho como se originando no "self-love" do indivíduo isolado, Smith se coloca no ponto de vista da concorrência. As "robinsonadas" de Smith são parte do que Marx chamava do "elemento vulgar" da Economia clássica; mais precisamente, Marx observa que Smith aborda a Economia por dois ângulos que correm paralelamente e em contradição:

O próprio Smith move-se com grande ingenuidade em contradição contínua. Ora investiga as conexões causais das categorias econômicas ou a estrutura oculta do sistema econômico burguês. Ora junta a essa pesquisa as conexões tais como se exteriorizam na aparência dos fenômenos da concorrência, se manifestam, portanto, ao observador não científico e, do mesmo modo, ao que está preso e interessado no processo da produção burguesa. Desses dois ângulos, um penetra no nexo causal, na fisiologia por assim dizer do sistema burguês; o outro apenas descreve, cataloga e relata, ajustando a definições esquematizantes o que se revela externamente no processo vital, tal como se mostra e parece: ambos, na obra de Smith, além de ocorrerem num paralelismo ingênuo, se misturam e se contradizem em contínuo (Marx, 1983, p. 597-598).

Desse modo, ao mesmo tempo em que, em suas "robinsonadas", o homem aparece em Smith na figura do indivíduo isolado e sem determinações sociais; na regulação do valor pelo trabalho contido na mercadoria nos tempos primitivos, há o reconhecimento implícito do vínculo social dos indivíduos por meio do trabalho (Marx, 1983).

Leituras contemporâneas da obra de Smith captam essa dualidade, descobrindo em Smith um indivíduo que não é apenas o autointeressado isolado e associal, mas um indivíduo socialmente determinado cujo comportamento depende da configuração institucional (Cerqueira, 2005; Screpanti; Zamagni, 2005).

Nessa abordagem, em Smith, o vínculo social seria tão parte da natureza humana quanto o "self-love". A propensão natural à troca seria a expressão de um "desejo de sociabilidade" sendo esta, e não o isolamento, a característica fundamental dos homens. Tal leitura, no entanto, é equivocada, uma vez que a propensão à troca é resultado da razão e da capacidade da 
fala, e não de um desejo, ou mais precisamente, de uma "paixão". ${ }^{3}$ A sociedade criada pela divisão do trabalho é resultado do autointeresse. Isso fica claro nos rascunhos de $A$ riqueza das nações, em que Smith identifica explicitamente a condição "primitiva" com o indivíduo isolado. ${ }^{4}$

Nessa linha, as restrições institucionais à plena manifestação da natureza humana não invalidam o ponto de partida no indivíduo autocentrado. É certo que Smith apresentou uma série de proposições legislativas e reformas institucionais. Contudo, tais reformas visariam ao "sistema natural de liberdade", isto é, à ordem natural, aquela que corresponderia à natureza humana, ao pleno exercício do "self-love" por parte de todos os indivíduos. Assim, na base do institucionalismo smithiano, há uma natureza humana imutável, definida por princípios universais que encontra obstáculos no sistema institucional pré-capitalista.

Isso coloca Smith no contexto geral do Iluminismo escocês. Segundo Redman (1997, p.110), para os escoceses, "o estudo da sociedade significa o estudo da natureza humana". A natureza humana pode ser compreendida a partir da observação, do contexto e da História. A descoberta de princípios básicos da natureza humana dar-se-ia pela observação do que há em comum nos diferentes dados históricos de distintas sociedades, e da introspecção. A ideia é que há uma natureza humana universal, motivações e comportamentos regulares que podem ser apreendidos racionalmente. Essa natureza pode ser percebida em sua forma mais pura no estágio primitivo ou no estado de natureza, em que as disposições básicas do homem aparecem tal como dadas pela natureza sem os obstáculos artificiais da civilização. Essas condições primitivas poderiam ser supostamente observadas nos povos naturais da América, onde os homens estariam no estado "selvagem e solitário" (Smith, 1982, p. 474).

3 Do mesmo modo, a simpatia não é em Smith um "desejo de sociabilidade", que motiva a ação do homem, como o "self-love", mas sim um princípio de julgamento moral conforme assinala Redman (1997). Essa questão remete ao desgastado debate sobre o "paradoxo de Smith", o qual foge diretamente ao tema deste artigo. Para o propósito deste artigo, basta assinalar que a simpatia não é uma "paixão", mas a base de uma restrição moral interna, decorrente da vida em sociedade, às paixões dos indivíduos.

4 "It cannot be very difficult to explain how it comes about that the rich and the powerful should, in a civilized society, be better provided with the conveniencies and necessaries of life than it is possible for any person to provide himself in a savage and solitary state. [...] Among savages, on the contrary, every individual enjoys the whole produce of his own industry" (Smith, 1982, p. 474). Pode parecer estranha a referência ao indivíduo isolado em uma tribo, mas, pelo menos em um momento, ao se referir a "tribes of animals" (Smith, 1982, p. 483) no mesmo manuscrito, Smith deixa entrever que a ligação tribal é meramente biológica, e não social. 
Deste modo, é somente na ordem natural, que corresponderia ao pleno exercício dos princípios da natureza humana, que se garante a liberdade para exercer o "self-love" e a felicidade dos indivíduos. Os escoceses olhavam a História com o objetivo de identificar "os obstáculos que impedem o curso natural do desenvolvimento" (Redman, 1997, p. 126), as coisas que impedem o progresso humano em direção à liberdade e à felicidade. A questão passa a ser de como garantir que as políticas e as instituições correspondam à ordem natural. Para a Economia Política clássica, bem como para a Filosofia Política clássica, as instituições que correspondem à ordem natural são aquelas do capitalismo: o mercado e a democracia representativa.

Marx critica a postura da Economia Política em relação à História, referindo-se à identificação da ordem natural com a ordem burguesa:

Os economistas têm procedimentos singulares. Para eles, só existem duas espécies de instituições, as artificiais e as naturais. As instituições da feudalidade são artificiais, as da burguesia são naturais. Nisto, eles se parecem aos teólogos, que também estabelecem dois tipos de religião: a sua é a emanação de Deus, as outras são invenções do homem. Dizendo que as relações atuais - as relações da produção burguesa - são naturais, os economistas dão a entender que é nestas relações que a riqueza se cria e as forças produtivas se desenvolvem segundo as leis da natureza. Portanto, estas relações são, elas mesmas, leis naturais independentes da influência do tempo. São leis eternas que devem sempre reger a sociedade. Assim, houve história, mas já não há mais (Marx, 1989, p. 115).

O reconhecimento do conflito de classes como central na Economia clássica pós-ricardiana e o próprio desenvolvimento desse conflito na sociedade capitalista levaram, segundo Marx (1996), a que o elemento vulgar da Economia clássica se destacasse, passando a ser uma teoria à parte.

A Economia neoclássica se apresenta como o desenvolvimento mais sistemático e bem-sucedido em termos de hegemonia no pensamento e na orientação de práticas econômicas da Economia vulgar. Aqui há a persistência da ideia de natureza humana, formulada como propensões universais dos indivíduos isolados, isto é, independentemente do contexto social e histórico. O Robinson Crusoé se torna a figura central e reina sozinho no pensamento econômico hegemônico a partir de então.

Os primeiros e principais autores da Economia neoclássica apresentam suas "robinsonadas" como princípio explicativo central do funcionamento da Economia. A perspectiva do indivíduo isolado aparece, por exemplo, em Walras, que distingue os fatos naturais, que têm origem nas forças cegas da natureza, dos fatos humanitários, que se originam do exercício da vontade do homem. De acordo com Walras, as pessoas são uma força 
clarividente e livre, e, assim, os homens têm a liberdade de subordinar as coisas - que não se conhecem e não se possuem - as suas finalidades, pelas quais eles são responsáveis já que se conhecem e se possuem.

Diante da existência de coisas "raras", isto é, coisas úteis e limitadas, a liberdade dos homens de subordinar as coisas gera o fato da apropriação. O fato da raridade torna as coisas "coercíveis ou apoderáveis", ou seja, podem ser recolhidas do uso comum por indivíduos. E estes o fazem porque sendo "clarividentes", isto é, racionais, sabem que essa apropriação atende a seus interesses, à satisfação de suas necessidades.

A apropriação gera, segundo Walras, o fato da troca. Claramente aqui a troca é colocada na perspectiva do indivíduo isolado. Sua origem está na propriedade privada, e seu móvel é o interesse dos indivíduos na satisfação de suas necessidades. Mais do que isso, da mesma forma que em Smith a troca é resultado de uma propensão natural dos homens, em Walras a troca aparece como um "fato natural", "natural em sua origem" - posto que a raridade e a decorrente apropriabilidade das coisas raras são um fato que se origina em forças cegas, as necessidades dos homens e a disponibilidade natural das coisas - "em sua manifestação e em sua maneira de ser". Assim segundo Walras:

\footnotetext{
Se o trigo e o dinheiro têm valor é porque são raros, isto é, úteis e limitados em quantidade, duas circunstâncias naturais. E se o trigo e o dinheiro têm tal valor, um em relação ao outro, é porque são, respectivamente, mais ou menos raros, isto é, mais ou menos úteis e mais ou menos limitados em quantidade, ainda duas circunstâncias naturais, as mesmas que as anteriores (Walras, 1996, p. 49).
}

A despeito disso, Walras admite a existência de relações entre pessoas e sua interdependência. Walras reconhece a existência da divisão do trabalho - resultante, segundo ele, de uma "aptidão fisiológica" do homem - e que "os destinos de todos os homens são solidários uns com os outros, do ponto de vista da satisfação de suas necessidades" (Walras, 1996, p. 55). Do mesmo modo, o autor constata que a repartição da riqueza, isto é, das coisas raras apropriadas, diz respeito à relação entre pessoas e que essa "é um fato humanitário que tem sua origem não na vontade individual de cada homem, mas na atividade coletiva de toda a sociedade" (Walras, 1996, p. 57). Deste modo, a repartição da riqueza é passível de um julgamento moral sobre sua forma correta de acordo com um princípio de justiça, segundo Walras.

Tais fatos, no entanto, são primeiramente deixados de fora da "economia política pura" que trata apenas do "fato do valor de troca". Ao colocar as questões relativas à divisão do trabalho na "economia aplicada" e, por- 
tanto, separada e distinta das questões relativas ao valor de troca, Walras elimina da "teoria econômica" o que Marx identificava como o elemento esotérico de Smith, o reconhecimento do caráter social do trabalho como base do valor. Em segundo lugar, o critério do juízo sobre a repartição da propriedade é colocado sob a perspectiva do indivíduo isolado. Ao colocar a equidade como critério de distribuição justa da riqueza, Walras afirma:

\section{Se cada um produzisse tudo o que consome e apenas consumisse o que produz, não apenas a sua produção seria regulada tendo em vista as necessidades de seu consumo, como seu consumo seria determinado pela amplitude de sua produção. Muito bem! Não é possivel que, em virtude da especificidade das ocupações, alguns de nós que tenham produzido pouco consumam muito, enquanto outros, que tenham produzido muito, consumam pouco (Walras, 1996, p. 55-56).}

Aqui, a ideia de uma ordem natural, de acordo com uma natureza humana imutável definida a partir do indivíduo isolado e sem determinações sociais presentes nas "robinsonadas" da Economia clássica, reaparece, ainda que formulada em outras bases, pois em Walras é o princípio da razão que dita a ordem que corresponde a justiça ou a distribuição equitativa da propriedade. Se antes havia história na teoria econômica - mesmo que fosse a história dos obstáculos sociais à ordem natural, identificada com a ordem instituída pela sociedade capitalista -, com a teoria neoclássica, ela já não existe mais.

A forma mais desenvolvida da "robinsonada" da Economia neoclássica é a explicação dos preços pela utilidade. Em Menger, por exemplo, o fundamento do valor na utilidade é explicado tomando como exemplo um indivíduo isolado sem nenhuma referência às relações sociais, tendo até mesmo uma referência explícita à Robinson Crusoé (Menger, 1983, p. 294-296). Como na teoria do valor de Menger, Robinson estabeleceu mentalmente a ordem de prioridade de suas necessidades em seu isolamento na ilha (Defoe, 1970).

Todo edifício teórico da Economia neoclássica e da Economia dominante de forma geral é construído sobre esse fundamento. Em sua forma moderna, assume-se o indivíduo racional com suas preferências e dotações como ponto de partida. As preferências e a racionalidade que determinam o comportamento do indivíduo carecem de determinações sociais, sua origem não é explicada ou quando muito se remete à explicação de origem biológica. Mantém-se assim a ideia de uma natureza humana imutável, acompanhada do indivíduo isolado sem determinações sociais como representação dessa natureza humana. 


\section{Origens das "robinsonadas": o indivíduo isolado e dependente do todo impessoal}

Além das imensas e reconhecidas dificuldades explanatórias que a ideia do homem isolado como fundamento da Economia apresenta, a perenidade dessa representação do homem requer uma explicação. Marx vai buscar a explicação dessa representação na forma como as relações sociais capitalistas se apresentam na consciência imediata. Assim segue o método da crítica ontológica em que as representações são remetidas em sua origem às relações reais e a forma necessária como elas se apresentam na consciência. ${ }^{5}$ Em outras palavras, trata-se de entender como a ideia do indivíduo isolado é possível valendo-se das relações de produção capitalistas.

Marx aponta que, a despeito da perenidade da representação do homem como indivíduo isolado na Economia Política, tal representação é um produto da História, e não da natureza: "Tal indivíduo do século XVIII é produto da dissolução das formas feudais de sociedade e, por outro lado, das novas forças produtivas desenvolvidas desde século XVI" (Marx, 2011, p. 39-40).

Dessa forma, o indivíduo isolado é primeiramente o produto da dissolução das relações pré-capitalistas. Já de forma bastante recuada, os indivíduos não existem e não eram percebidos como isolados, mas apenas como membros de uma tribo. Marx assinala que a propriedade nessas condições significa um comportamento duplo: subjetivo - como pertencimento a uma tribo, como "membro de uma entidade comunitária" - e objetivo - do solo como seu, como propriedade coletiva que é ao mesmo tempo posse individual, como comportamento com a terra como "pressuposto pertencentes a sua individualidade" (Marx, 2011, p. 403-404). Nessa concepção, os indivíduos se identificam e realmente existem como parte de uma comunidade.

Havia a propriedade como algo pertencente a uma comunidade marcada primordialmente pelos laços de sangue. Tal pressuposto continua na idade feudal com as linhagens. Conforme assinala Bloch (1982, p. 153), as linhagens funcionavam na prática como o fundamento de "uma sociedade de bens", mesmo onde a propriedade e a posse individuais eram legítimas.

5 A crítica ontológica é o termo utilizado por Lukács (1979) para designar a metodologia de Marx. Tal método é empregado na crítica da filosofia especulativa alemã em $A$ ideologia alemã (Marx; Engles, 2007) e na crítica da Economia Política em O capital. 
Não só os benefícios e os deveres da propriedade eram compartilhados pelos membros de uma linhagem como, mesmo onde a posse era reconhecida como individual, a alienação da terra ficava subordinada à aprovação do maior número de parentes possível (Bloch, 1982).

Aqui as relações reais colocavam os indivíduos como membros de um vasto grupo familiar para além das questões de cunho meramente econômico, uma vez que os parentes serviam de apoio e até mesmo de juiz em questões de disputas, bem como toda a linhagem era culpada de um crime: "De tal modo o indivíduo e o grupo pareciam inseparáveis" (Bloch, 1982, p. 148).

$\mathrm{Na}$ feudalidade, porém, as relações de dependência e subordinação iam além do grupo familiar. De acordo com Bloch (1982), independentemente das mais variadas formas que tomou em diferentes lugares e momentos no tempo, "o elemento fundamental comum" das relações feudais era "a subordinação de indivíduo a indivíduo" (Bloch, 1982, p. 168). Nesse sentido, aponta Bloch, o vocabulário comum e difundido na feudalidade era o "ser homem de outro homem" (Bloch, 1982, p. 168).

Marx assinala que, nas sociedades feudais, "em vez do homem independente, encontramos aqui todos dependentes - servos e senhores feudais, vassalos e suseranos, leigos e clérigos. A dependência pessoal caracteriza tanto as condições sociais da produção material quanto as esferas de vida estruturadas sobre ela" (Marx, 1996, p. 202) e que nessas condições, o estamento é "uma qualidade inseparável de sua individualidade" (Marx; Engels, 2007, p. 65).

Marx observa que as relações de dependência pessoal são primeiras formas de desenvolvimento - limitado - da produtividade. Em sociedades com baixo desenvolvimento das forças produtivas e onde o produtor direto mantém a posse dos instrumentos de produção, a extração de trabalho excedente ocorre "mediante coerção extraeconômica, qualquer que seja a forma que esta assuma. [...]. Por isso, para funcionar o sistema precisa de relações pessoais de dependência, de subordinação pessoal [...]" (Marx, 1981, p. 906-907).

$\mathrm{Na}$ produção corporativa artesanal urbana medieval, as relações entre mestres, oficiais e aprendizes se estabeleciam de forma patriarcal, com o mestre ocupando um lugar hierarquicamente superior em decorrência de sua maior habilidade no ofício (Marx, 1985, p. 98), e o artesão aprendiz, "de forma patriarcal comparte a mesa como o mestre", e o oficial é possuidor do fundo de consumo do mestre (Marx, 2011, p. 408). 
Em resumo, nas relações pré-capitalistas, os indivíduos aparecem diretamente e de forma clara sob uma determinação social: como membros de uma comunidade - seja uma linhagem, seja um feudo, seja uma corporação - e determinados pela sua relação com o outro - como mestre, aprendiz ou oficial, como servo, senhor ou parente.

São esses vínculos comunitários e a determinação social direta dos indivíduos por suas relações pessoais que são dissolvidos pela produção generalizada de mercadorias característica da produção capitalista: "O ser humano só se individualiza pelo processo histórico. Ele aparece originalmente como ser genérico, ser tribal, animal gregário [...]. A própria troca é um meio essencial dessa individuação. Ela troca o sistema gregário supérfluo e o dissolve" (Marx, 2011, p. 407). Surge, então, o indivíduo isolado na aparência imediata dessa sociedade, não só na sua representação artística e científica, como de fato na consciência cotidiana. Essa consciência tem uma base real que é visível na possibilidade presente na sociedade capitalista contemporânea, de um indivíduo satisfazer suas necessidades materiais em isolamento por longo período, mesmo sem ter sido o único sobrevivente de um naufrágio como Robinson Crusoé.

Essa base real e sua representação na consciência advêm das condições em que se colocam a produção mercantil generalizada. Tais condições consistem primeiramente na divisão social do trabalho desenvolvido, em que o trabalho já não está mais condicionado pela hierarquia e regulação corporativa ou pelo sistema de castas. A segunda condição para a produção generalizada de mercadorias é a propriedade privada móvel, isto é, aquela que não está fixa em um instrumento de trabalho ou na terra; "apenas produtos de trabalhos privados autônomos e independentes entre si confrontam-se como mercadorias" (Marx, 1996, p. 171).

Os produtores privados de mercadorias se apresentam uns em relação aos outros primeiramente como independentes, já que cada um como proprietário privado de uma mercadoria deve ser livre juridicamente para poder dispor de acordo com os interesses de sua propriedade. Além disso, os produtores privados de mercadorias se enfrentam como autônomos: as decisões de cada produtor independem da relação direta com o outro produtor, isto é, cada produtor não é coagido ou precisa se associar com o conjunto dos outros produtores para determinar o que, quanto e como produzir.

Dessa forma, cada indivíduo aparece, portanto, isolado de outros indivíduos, apenas exercendo sua livre vontade (liberdade); igual aos outros, 
sem subordinação hierárquica (igualdade); dispondo somente do que é seu (propriedade) e cuidando de si mesmo (Bentham). $O$ único poder que os junta e leva a um relacionamento é o proveito próprio, a vantagem particular, os seus interesses privados. A cada produtor/vendedor de mercadoria o outro aparece apenas como um proprietário capaz de realizar sua mercadoria, como dono do dinheiro (comprador). Isto é, cada um aparece como meio de atender às necessidades, aos desejos e aos interesses do outro.

Esse isolamento do indivíduo, no entanto, traduz apenas a aparência na superfície - e consequentemente na consciência cotidiana e sua representação artística e científica - das relações sociais no capitalismo. Isso porque o pressuposto para o isolamento dos indivíduos é a ampliação de suas relações de dependência no que diz respeito ao conjunto da sociedade. $O$ indivíduo isolado supõe o aprofundamento e a ampliação dos vínculos entre os indivíduos, não sendo, portanto, uma situação "natural" e/ou "original".

Com base nessa compreensão, o isolamento de Robinson não é uma situação original, mas foi possibilitado por todas as relações sociais que ele carrega. Relações essas que aparecem nas condições materiais encontradas no barco e na sua capacidade desenvolvida na sociedade em que se formou como indivíduo. Nessa abordagem, afirma Marx que "a produção do singular isolado fora da sociedade [...] pode muito bem ocorrer a um civilizado, já potencialmente dotado das capacidades da sociedade, por acaso perdido na selva" (Marx, 2011, p. 40).

Marx assinala que a época que produz o ponto de vista do indivíduo isolado "é justamente a época das relações sociais (universais desde esse ponto de vista) mais desenvolvidas até o presente" (Marx, 2011, p. 40). Os vínculos sociais existem aqui porque, apesar de privados, esses trabalhos são parte do trabalho social, e esse se encontra em sua forma "mais desenvolvida", segundo ele, porque está liberto dos limites estreitos das relações anteriores.

A ampliação dos limites se refere primeiramente à extensão e à ampliação da divisão do trabalho: com a divisão manufatureira, no interior de um processo de produção, e a libertação das castas e das corporações, apresenta-se uma grande variedade de trabalhos - para um indivíduo e socialmente - e consequentemente de produtos a cada momento no tempo e ao longo do tempo. Tal ampliação da divisão do trabalho implica e requer uma ampliação das relações sociais, seja em sua variedade, seja em sua extensão no espaço. 
O mesmo acontece em relação à propriedade privada móvel, isto é, a propriedade privada representada no dinheiro, e não mais fixa na terra ou em um instrumento de produção, possibilita uma variedade e a ampliação das relações sociais. Diante da generalização das relações monetárias e da forma mercantil, os indivíduos estão vinculados uns aos outros e ocupam posições sociais as mais variadas por meio da posse e do uso do dinheiro. Marx até reconhece que o "mercado mundial" coloca as bases materiais de uma sociedade mundial e o consequente reconhecimento de uma humanidade como gênero humano (Marx; Engels, 2007, p. 60).

Finalmente, as relações sociais "mais desenvolvidas" se referem ao imenso desenvolvimento das forças produtivas como forças coletivas, sociais do trabalho na sociedade capitalista. Aqui os indivíduos se encontram em cooperação na produção, seja diretamente no local de produção, seja indiretamente por meio da transformação da Ciência em uma força produtiva. Neste último caso, Marx ser refere a um "trabalho universal", já que a produção científica - que se entrelaça com a produção material tem como condição "além da cooperação com os vivos, a utilização dos trabalhos dos antecessores" (Marx, 1981, p. 116), ou seja, pressupõe todo o desenvolvimento anterior da humanidade.

Mas, se na sociedade capitalista os vínculos sociais se ampliam em extensão e variedade, por que esses vínculos não aparecem de forma clara e imediata na representação do homem na sociedade capitalista, em especial na Economia? Marx identifica a resposta a essa questão na forma dessa dependência recíproca e "do caráter social peculiar do trabalho que produz mercadorias" (Marx, 1996, p. 199).

O trabalho que produz mercadorias é ao mesmo tempo privado - em decorrência da propriedade privada - e social, graças à divisão do trabalho. Como pode o trabalho ser social e privado ao mesmo tempo? Trabalhos privados se validam como sociais através dos seus produtos, das mercadorias, e o caráter social é posto post festum. $\bigcirc$ trabalho de cada produtor privado só se relaciona com os dos outros como trabalho igual, geral, abstrato, e não na sua forma concreta.

Por isso, assinala Marx, as relações de dependência mútua na produção mercantil capitalista não aparecem diretamente entre indivíduos socialmente determinados, e sim como a dependência de cada um no que concerne às coisas, às mercadorias. Os vínculos diretos entre os produtores são substituídos pelos vínculos de valor entre as mercadorias. Marx afirma 
que "em outras palavras, os trabalhos privados só atuam, de fato, como membros do trabalho social total por meio das relações que a troca estabelece entre os produtos do trabalho e, por meio dos mesmos, entre os produtores" (Marx, 1996, p. 199).

Na seção do fetiche da mercadoria em $O$ capital, Marx aponta a especificidade desse modo de ser do trabalho social no capitalismo perante outras sociedades. Nas relações pré-capitalistas, o trabalho se afirma como social por meio de vínculos pessoais diretos, na família, na comunidade, ou de vínculos de subordinação pessoais diretos. $O$ caráter social está no fato de que satisfazem necessidades sociais, e suas ligações são mediadas por outras relações sociais não diretamente ou puramente econômicas. Nessas sociedades, o trabalho ganha seu caráter social por intermédio desses elos.

Em outras palavras, o trabalho não aparece com o vínculo entre as pessoas na sua reprodução material; no caso da Idade Média, são as relações de dependência pessoal que se estabelecem por meio de tradições, costumes, força. No feudalismo, pelo fato de as relações de dependência pessoal constituírem o laço social, o trabalho e seus produtos "entram na engrenagem social como serviços e pagamentos em natura. A forma natural do trabalho, sua particularidade, e não, como na base da produção de mercadorias, a sua generalidade, é aqui sua forma diretamente social (Marx, 1996, p. 203).

Assim, enquanto nas sociedades pré-capitalistas as relações econômicas aparecem imbricadas em outras relações sociais, com a produção mercantil é diretamente por meio da ligação entre trabalhos que os vínculos da produção material se estabelecem. Assim, cada um obtém o que necessita dos outros por meio do trabalho, seja por meio dos produtos de seu trabalho - mercadorias -, seja por meio do próprio trabalho - caso da venda da força de trabalho - seja por meio do trabalho dos outros - caso da mais-valia (Postone, 1993).

Desse modo, o trabalho adquire caráter abstrato, uma vez que cada um obtém o produto dos outros de que necessita, independentemente do conteúdo concreto de seu trabalho e do conteúdo do trabalho dos outros (Postone, 1993). Da mesma forma, os vínculos sociais na reprodução material só podem se dar por meio dos produtos do trabalho, já que eles acontecem diretamente por meio da reprodução material entre produtores privados, independentes.

Marx observa que a mercadoria "[...] reflete aos homens as características sociais do seu próprio trabalho como características objetivas dos próprios produtos de trabalho, como propriedades naturais sociais dessas coi- 
sas encobrem as características sociais próprias do trabalho" (Marx, 1996, p. 198); aquilo que é característica da atividade social dos homens aparece como uma característica ou propriedade das coisas, seja ela mercadoria, seja valor, seja capital sob a forma de meios de produção. É nesse ponto que Marx identifica o fetiche da mercadoria, ou seja, o fato de que "determinada relação social entre os próprios homens que para eles aqui assume a forma fantasmagórica de uma relação entre coisas" (Marx, 1996, p. 198). O valor, portanto, é uma relação social entre produtores que assume a forma de relações entre coisas. O caráter social do trabalho se apresenta na sociedade capitalista como qualidade material das coisas.

Esses vínculos sociais, ao se estabelecerem por meio dos produtos do trabalho, não são percebidos imediatamente na ação dos produtores de mercadorias: "O que, na prática, primeiro interessa aos que trocam produtos é a questão de quantos produtos alheios eles recebem pelo seu, em quais proporções, portanto, se trocam os produtos" (Marx, 1996, p. 200). As relações podem se firmar sem que os produtores e os envolvidos nela o saibam - tem caráter impessoal, uma vez que o vínculo social mercantil não requer a interação direta entre os produtores (Postone, 1993). Ao comprar um produto produzido a milhares de quilômetros de distância, cria-se um vínculo com aqueles produtores sem que seja necessária qualquer relação direta e imediata com eles. Desta forma, a produção material não é consciente: "Ao equiparar seus produtos de diferentes espécies na troca, como valores, equiparam seus diferentes trabalhos como trabalho humano. Não o sabem, mas o fazem" (Marx, 1996, p. 200).

Se os produtores não têm consciência de seus vínculos e esses estão atados a seus produtos, embora valor, mercadoria e capital sejam "um produto social dos homens", uma criação histórica aparece como "algo natural e definitivo". Como produtos com características físicas, naturais, determinadas, parece que as propriedades "sociais" das mercadorias são tão eternas e naturais quanto às físicas. Apresentam-se assim como um produto da natureza, e não das próprias relações dos homens.

Esse ponto de vista fetichizado que naturaliza e eterniza no pensamento as relações sociais capitalistas é o ponto de vista da Economia Política, segundo Marx. Ao colocar a troca e o valor nos "estágios primitivos" da sociedade, Smith hipostasia as relações de produção capitalistas, e Ricardo vai ainda mais longe ao colocar também o capital nesse estágio (Marx, 1996, p. 202, n. 115). Esse ponto de vista de naturalização das relações 
capitalistas chega ao seu auge na Economia neoclássica, por exemplo, em Menger, ao colocar a origem do valor em uma relação abstrata entre o juízo dos indivíduos sobre suas necessidades e a disponibilidade dos "bens" ou mais claramente em Walras, ao classificar a Economia Política pura como uma Ciência Natural.

Contudo, para além do caráter não consciente e a consequente naturalização das relações capitalistas, os homens se tornam subordinados às coisas. Nenhum produtor diz ou impõe ao outro o que, quanto ou como produzir, mas é o movimento da circulação das mercadorias que impõe a cada um a determinação de sua produção. Embora livre da dependência pessoal, cada produtor é dependente e subordinado ao "mercado", isto é, ele não é livre para produzir o que quer, quanto quer e como quer, visto que a realização dos seus interesses/desejos/necessidades privados dependem da venda da mercadoria a um certo valor. "Seu próprio movimento social possui para eles a forma de um movimento de coisas, sob cujo controle se encontram, em vez de controlá-las" (Marx, 1996, p. 200). Essa dependência e subordinação é imposta por um mecanismo impessoal, o mecanismo da concorrência. A concorrência é a forma como o caráter social da produção se impõe para cada produtor privado.

A Economia Política não captura plenamente essa dependência recíproca e sua forma alienada já que esta não é visível imediatamente. A Economia Política adota o ponto de vista da concorrência, da esfera da circulação e, quando o faz, recai no que Marx denomina de "economia vulgar". A adoção do ponto de vista da concorrência corresponde à imagem do homem isolado, cujo vínculo imediato é com as coisas, e o vínculo com os outros se dá unicamente por meio das coisas. Marx afirma que "a concorrência isola os indivíduos uns dos outros" (Marx; Engels, 2007, p. 62).

\section{0 indivíduo em Marx}

É comum que a crítica de Marx ao ponto de vista do indivíduo isolado seja confundida com uma desconsideração da importância teórica ou ética do indivíduo. Do ponto de vista teórico, predominam leituras, tantos de críticos como de supostos apoiadores, ${ }^{6}$ em que Marx teria adotado um ponto de

6 Por exemplo, Popper (1966), dentre os críticos, e Althusser (1979), dentre os apoiadores. 
vista "estruturalista" ou "holista" em abstrato nas suas explicações teóricas para o funcionamento das sociedades de modo geral. Do ponto de vista ético, é comum também entre críticos e apoiadores entender que a sociedade comunista seria a da subordinação do indivíduo ao todo social. Nesta seção, procura-se apontar algumas consequências, tanto teóricas como ético-políticas, da crítica de Marx às "robinsonadas" da Economia Política.

Cabe ressaltar primeiramente que a crítica de Marx recai sobre o indivíduo isolado da teoria econômica e sobre o isolamento do indivíduo na realidade da sociedade capitalista. Não se trata, portanto, de uma crítica ao indivíduo em abstrato, isto é, uma crítica que se refira ao indivíduo livre de qualquer determinação. Isso tanto do ponto de vista teórico como ético-político.

Em Marx, não está presente a contraposição excludente entre o indivíduo isolado, no qual a sociedade seria uma coleção de átomos, e a sociedade como "abstração frente aos indivíduos", na qual os indivíduos seriam mera expressão das necessidades/finalidades/mecanismos do todo social. Tal contraposição é produto das relações reais da sociedade capitalista, em que os indivíduos só podem se isolar quando a sociedade se torna uma abstração diante deles.

Ao contrário dessa contraposição excludente na teoria, Marx apreende a sociedade como "a soma de vínculos, relações em que se encontram esses indivíduos uns como os outros" (Marx, 2011, p. 205). E os indivíduos são determinados socialmente, indivíduos cuja ação depende de condições que não são postas a cada momento por eles. Assim, para Marx, o elemento fundamental que constitui a sociedade e pelo qual se pode compreendê-la teoricamente são as relações sociais.

A essa perspectiva poderia ser contraposta a afirmação de Marx em $O$ Capital de que "os personagens econômicos encarnados pelas pessoas nada mais são que as personificações das relações econômicas, como portadores das quais elas se defrontam" (Marx, 1996, p. 210). Nesse sentido, os produtores de mercadorias são apenas produtores privados, e o capitalista é "persona" do capital.

Mas isso, por um lado é resultado das relações capitalistas de produção que colocam os indivíduos como impotentes perante suas relações. Por outro lado, isso não significa que os indivíduos não tenham possibilidade de ação no interior dessas relações e uma personalidade própria ou de que as leis de funcionamento da sociedade capitalista possam operar sem a ação - socialmente determinada - dos indivíduos. 
Este último ponto é apreensível em $O$ Capital na explicação da geração de mais-valia relativa, isto é, produto não intencional da ação dos capitalistas individuais. Cada capitalista age com a finalidade de aumentar a mais-valia de que se apropria, impelido pela concorrência. Para tanto, dadas as condições sociais que restringem a ampliação desmesurada da jornada de trabalho, procuram métodos que aumentem a produtividade. Ao introduzir métodos mais produtivos que a média de um ramo de produção, cada capitalista acaba por obter uma mais-valia extraordinária. Como todos os capitalistas estão sob as mesmas condições gerais - busca de aumento da mais-valia impelida pela concorrência -, o movimento se generaliza atingindo os ramos que produzem os meios de subsistência dos trabalhadores, rebaixando o valor da força de trabalho e gerando mais-valia relativa. Deste modo, embora cada capitalista vise aumentar sua mais-valia em relação aos outros, o resultado geral é o aumento de mais-valia para o capital como um todo.

A explicação da mais-valia relativa deixa claro como a relação entre indivíduo e sociedade é apreendida por Marx. Os indivíduos buscam em suas ações realizar determinadas finalidades. Nos termos colocados por Lukács (1979), a característica específica do ser social é o agir teleológico, a ação que põe no mundo objetividades até então inexistentes. A realização do agir teleológico coloca sempre os indivíduos diante de alternativas. Mas a síntese da ação teleológica dos indivíduos resulta em legalidades que "são independentes da vontade, consciência e intenção dos homens" (Marx, 1996, p. 139). Assim, afirma Lukács, ao ser referir à "estrutura fundamental dos processos sociais":

[...] eles partem imediatamente de posições teleológicas, determinadas em sentido alternativo, feitas por homens singulares; todavia, dado o decurso causal das posições teleológicas, essas desembocam num processo causal, contraditoriamente unitário, dos complexos sociais em sua totalidade, e produzem conexões legais universais (Lukács, 1979, p. 95).

Contudo, ao mesmo tempo, a ação teleológica e as escolhas dos indivíduos não se dão em uma condição abstrata, livre de determinações sociais. Conforme apontado na explicação da mais-valia relativa, os capitalistas tomam suas decisões condicionados por sua posição de capitalistas, isto é, impelidos pelo motivo do lucro e coagidos pela concorrência. Desse modo, ao se referir à origem da mais-valia relativa na busca de mais-valia extraordinária por cada capitalista, Marx aponta que "[...] as leis imanentes da produção capitalista aparecem no movimento externo dos capitais, [...] se impõem 
como leis coercitivas da concorrência e assim surgem na consciência do capitalista individual como motivos impulsionadores" (Marx, 1996, p. 433).

O papel do agir teleológico na formação de processos sociais de natureza causal é também apreensível na realização da mercadoria, a sua venda. Nesse caso, o dinheiro se põe como ideal, objetivo a ser alcançado para o possuidor da mercadoria, e, por outro lado, o dinheiro não realiza seu valor de uso enquanto não for trocado pela mercadoria (Marx, 1982, p. 71). Assim, na troca da mercadoria, "cada termo extremo é idealmente o que seu contrário é realmente e vice-versa" (Marx, 1982, p. 71). A realização da mercadoria depende, nesses termos, do confronto de atos teleológicos alternativos; conforme assinala Lukács, "duas posições teleológicas, uma dirigida à outra, fazendo surgir uma interação na qual em ambos os lados se verifica uma transformação do ideal em real" (Lukács, 1976, p. 340).

Da mesma forma que na produção de mais-valia relativa, também no caso da venda da mercadoria não se trata de atos teleológicos de indivíduos carentes de determinação social, incondicionais ou condicionados por uma natureza humana eterna e imutável. Se por um lado os indivíduos podem decidir em cada ato de troca comprar ou não a mercadoria, por outro essa decisão é constrangida pela sua posição de comprador ou vendedor. Nesse ponto, Marx é explícito quanto ao caráter socialmente determinado da individualidade e adicionalmente apresenta uma crítica à propensão natural à troca de Smith, que identifica a individualidade socialmente determinada com a individualidade humana em si:

Estes caracteres sociais determinados não surgem absolutamente da individualidade humana, mas sim das relaçoes de troca dos homens que produzem os seus produtos na forma determinada de mercadoria. [...] Conceber esses caracteres economicamente burgueses de comprador e vendedor como formas sociais eternas da individualidade humana é tão ridículo quanto é absurdo deplorá-las como aniquiladoras da individualidade. Constituem manifestação da individualidade em uma determinada etapa do processo de produção social (Marx, 1982, p. 74).

Dessa forma, os atos individuais e os seus produtos sociais estão em relação de interação dialética. $O$ erro da Economia Política em seu elemento vulgar é tomar unilateralmente um desses lados de uma unidade dialética. Conforme afirma Lukács:

[...] todas essas relações, processos, etc. objetivos, mesmo continuando a existir $e$ agir independentemente das intenções dos atos humanos individuais que os realizam, só emergem à condição de ser enquanto realizações desses atos e só podem explicitar-se ulteriormente retroagindo sobre novos atos humanos individuais (Lukács, 1979, p. 83). 
Nessa direção, a determinação social dos indivíduos leva à conclusão de que o "self-love" ou o autointeresse como móvel da ação não é uma característica definidora de uma natureza humana universal, mas sim um componente dessa determinação social. Da mesma forma, pode se concluir que, ao falar dos indivíduos como "personificação das relações sociais", Marx se refere ao seu "papel econômico" à determinação de sua ação pela posição que ocupam na estrutura econômica da sociedade capitalista. É importante desenvolver esse ponto para não recair na visão de que todas as ações de todos os indivíduos são apenas a expressão das legalidades sociais.

Em tese, um capitalista pode escolher não se dobrar aos imperativos da concorrência e da busca de mais-valia. Mas o indivíduo que fizer tal escolha muito provavelmente deixará a posição social de capitalista e possivelmente vai à condição de trabalhador. Mais importante é que, em diversas partes de sua obra, Marx aponta que os indivíduos podem fazer essas escolhas, embora não seja possível aos indivíduos fazê-lo em massa:

[...] uma análise dessas relações externas, dessas condições, mostra a impossibilidade dos individuos de uma classe, etc. De superá-las em massa sem as abolir. O indivíduo singular pode casualmente ser capaz de fazêe-lo; a massa de indivíduos dominados por tais relações não pode, uma vez que sua mera existência expressa a subordinação, a necessária subordinação dos indivíduos a elas (Marx, 2011, p. 111).

caráter de "personificação" das relações econômicas atribuído aos indivíduos não é de acordo com Marx uma condição ontológica da natureza humana, mas um produto dessas mesmas relações que subsumem e dominam os indivíduos: "Por outro lado, a classe se autonomiza, por sua vez, em face dos indivíduos, de modo que estes encontram condições de vida predestinadas e recebem já pronta da classe sua posição na vida e, com isso, seu desenvolvimento pessoal; são subsumidos a ela" (Marx; Engels, 2007, p. 63).

Essas mesmas relações colocam os indivíduos diante do caráter contingente de sua vida e de sua determinação de classe. Além do mais, uma vez que os vínculos das relações materiais se autonomizam diante de outros vínculos sociais e dos próprios indivíduos, esses passam a ter uma vida pessoal separada de sua posição social. Assim, Marx se refere à "divisão da vida do indivíduo entre vida pessoal e vida subsumida a um ramo de trabalho e às condições a ele correspondentes", isto é, a diferença entre o "indivíduo pessoal" e o "indivíduo de classe" (Marx; Engels, 2007, p. 65). Dessa maneira, as "personas" não deixam de ser pessoas, como afirma 
Marx: "Não se deve entender por isso como se, por exemplo, o rentista, o capitalista, etc., deixassem de ser pessoas, mas sim no sentido de que sua personalidade é condicionada e determinada por relações de classe bem definidas" (Marx; Engels, 2007, p. 65).

Todos esses aspectos levam a considerações sobre a crítica de Marx às relações capitalistas e ao projeto emancipatório que dela se deriva. Do ponto de vista ético-político, Marx era um pensador da liberdade. Sua crítica ao liberalismo dos economistas consiste no fato de que esses tomam a emancipação dos indivíduos de relações de subordinação direta com outros indivíduos como sendo a liberdade em abstrato. $\mathrm{O}$ isolamento do indivíduo é tomado como sinônimo de sua emancipação; replica-se aqui na teoria econômica o discurso de Robinson Crusoé como defensor da liberdade - entendida nesse sentido - com valor ético máximo. Robinson afirma que a liberdade é seu objetivo (Defoe, 1970), mas fica evidente no livro que somente no isolamento foi capaz de experimentá-la.

Em vários textos ao longo de sua obra, Marx reconhece o caráter emancipatório das relações capitalistas que abolem as relações de subordinação direta no seu funcionamento normal. Mas, se as relações capitalistas libertam os homens da coerção e da subordinação pessoal direta, colocam-nos ao mesmo tempo subordinados e coagidos pelas forças impessoais do mercado, criado por suas relações.

A liberdade para Marx é sempre uma liberdade concreta, e não em abstrato; liberdade significa sempre liberdade em determinadas condições. Assim, ao se referir à libertação da servidão, Marx afirma que essa "constituiu a asseveração da individualidade dos servos da gleba e, ao mesmo tempo, a derrubada de uma determinada barreira empírica" (Marx; Engels, 2007, p. 292). Dessa forma, a emancipação é um processo em que "uma capacidade que existia apenas como potencialidade nos indivíduos [...] é confirmada como poder real ou ampliada pela supressão de uma barreira" (Marx; Engels, 2007, p. 292).

Assim, ao contrário do que parece no discurso de vários interpretes e críticos, Marx não apontava para a subordinação do indivíduo à sociedade "abstrata" como modo de superação desejável e possível ao capitalismo. Ao contrário, Marx apreendia no capitalismo a possibilidade de construção de uma sociedade que permitisse o "livre e pleno desenvolvimento de todos os indivíduos". Esse é o princípio orientador da sociedade comunista, que pode ser encontrado na obra de Marx. 
Mas, como a ação dos indivíduos é socialmente determinada, como esses estão sempre postos em determinadas relações, esse livre e pleno desenvolvimento não pode ser realizado pelos indivíduos isolados. Nesse contexto, Marx afirma que "é somente na comunidade [com outros que] cada indivíduo tem os meios de desenvolver suas faculdades em todos os sentidos; somente na comunidade, portanto, a liberdade pessoal torna-se possível" (Marx; Engels, 2007, p. 64).

Todavia, é preciso assinalar que a "comunidade" a que Marx se refere aqui não é o Estado. Ao contrário disso, Marx assinala que o Estado é uma "comunidade ilusória", uma comunidade que se autonomiza perante o indivíduo (Marx; Engels, 2007, p. 64). Ao Estado Marx contrapõe a livre associação dos indivíduos. Essa não é a imposição de uma coletividade sobre o indivíduo, mas uma coletividade formada por indivíduos - "associação de indivíduos", em que "os indivíduos participam como indivíduos" (Marx; Engels, 2007, p. 66), e não como proprietários privados, trabalhadores, capitalista ou cidadãos.

Assim, em Marx, não há simplesmente uma contraposição ético-político entre coletividade "abstrata" e indivíduos isolados. Marx infere valorações muito negativas de determinadas formas de coletividades - justamente aquelas que se contrapõem e subsumem os indivíduos, como as classes e o Estado. Portanto, Marx não coloca o Estado como a forma de coletividade que supera o indivíduo isolado. $O$ indivíduo isolado é superado pelos indivíduos livremente associados ou pela associação de indivíduos. A contraposição entre o Estado como representando a coletividade e o mercado como meio de colisão dos indivíduos isolados é algo do interior do capitalismo - e em sua expressão teórica, da Ciência Econômica.

Em resumo, a crítica de Marx ao isolamento dos indivíduos como produto das relações capitalistas e à representação do indivíduo isolado na Economia Política se alicerça na liberdade como princípio ético do desenvolvimento do homem. Mas, como não se trata da liberdade em abstrato, com sentido meramente negativo, o "livre e pleno desenvolvimento de todos os indivíduos" requer o rompimento das relações que tornam o indivíduo isolado e alienado das condições de sua ação. 


\section{Referências}

ALTHUSSER, L. et al. Para ler o capital. Rio de Janeiro: Zahar, 1979.

BLOCH, M. A sociedade feudal. Lisboa: Edições 70, 1982.

CERQUeIRA, H. E. A. G. Para ler Adam Smith: Novas abordagens. Sintese, Belo Horizonte, v. 32, n. 103, 2005.

DEFOE, D. Robinson Crusoé. Rio de Janeiro: Ediouro, 1970.

LUKÁCS, G. Per l'ontologia dell'essere sociale. Roma: Riuniti, 1976.

LUKÁCS, G. Ontologia do ser social. Os princípios ontológicos fundamentais de Marx. São Paulo: Ciências Humanas, 1979.

LUKÁCS, G. O romance como epopeia burguesa. In: LUKÁCS, G. Arte e sociedade. Escritos Estéticos 1932-1967. Rio de Janeiro: Editora da UFRJ, 2009.

MAC INTYRE, A. A short history of ethics. New York: Macmillam, 1996.

MARX, K. O capital. Crítica da Economia Política. Livro III. O processo global de produção capitalista. Rio de Janeiro: Civilização Brasileira, 1981.

MARX, K. Para a crítica da Economia Politica. Série Os Economistas. São Paulo: Nova Cultural, 1982.

MARX, K. Teorias da mais-valia. São Paulo: Difel, 1983.

MARX, K. Capitulo VI inédito de O capital. Resultados do processo de produção imediata. São Paulo: Moraes, 1985.

MARX K. A Miséria da Filosofia. São Paulo: Global, 1989.

Marx K. O capital. Crítica da Economia Política. Livro I. O processo de produção do capital. 2 Volumes. Série Os Economistas. São Paulo: Nova Cultural, 1996.

MARX, K. Grundrisse. São Paulo: Boitempo/UFRJ, 2011.

MARX, K.; ENGELS, F. Ideologia alemã. São Paulo: Boitempo, 2007.

MENGER, C. Princípios de Economia Política. São Paulo: Abril Cultural, 1983.

POPPER, K. The open society and its enemies. vol. II. Hegel and Marx. Princenton University Press, 1968.

POSTONE, M. Time, labour and social domination. New York: Cambridge University Press, 1993.

REDMAN, D. The rise of Political Economy as a science. methodology and the classical economists. Massachusetts: The MIT Press Cambridge, 1997.

RICHETTI, J. The life of Daniel Defoe. A critical biography. Oxford: Blackwell, 2005.

SCREPANTI, E.; ZAMAGNI, S. On the outline of the History of Economic Thought. Oxford: Oxford University Press, 2005.

SMITH, A. Lectures on jurisprudence. Glasgow editions of the works and correspondence of Adam Smith. Indianapolis: Liberty Fund, 1982.

SMITH, A. A riqueza das nações: Investigação sobre sua natureza e suas causas. Coleção Os Economistas. São Paulo: Abril Cultural, 1983. 
WALRAS, L. Compêndio dos elementos de Economia Política pura. São Paulo: Nova Cultural, 1996.

WATT, I. The rise of the novel. Studies in Defoe, Richardson and Fielding. Berkeley: University of California Press, 1957.

WATT, I. Myths of modern individualism. Faust, Don Quixote, Don Juan, Robinson Crusoé. Cambridge: Cambridge University Press, 1996.

\section{Sobre os autores}

André Guimarães Augusto - andre@economia.uff.br

Professor associado do Departamento de Economia / Pesquisador do NIEP-MARX, UFF, Niterói, RJ.

\section{Sobre 0 artigo}

Recebido em 16 de agosto de 2013. Aprovado em 18 de fevereiro de 2015. 